\title{
A importância da Educação Financeira nos conteúdos curriculares dos cursos
}

\section{The importance of Financial Education in the curricular contents of the courses}

\author{
Elton Pereira Dias ${ }^{1}$ \\ Marcelo dos Santos ${ }^{2}$
}

\begin{abstract}
Resumo
Abstract

O artigo apresenta um estudo acadêmico sobre a importância da inserção da educação financeira na grade curricular das escolas e universidades do Brasil, e a partir de pesquisas, abordar características do nível de conhecimento atual fornecido pelos processos de ensino e aprendizagem nas diversas etapas de formação dos brasileiros. A metodologia utilizada para o estudo caracterizou-se de Pesquisa Exploratória com elementos quantitativos e Pesquisa Bibliográfica. Foram realizadas pesquisas em Instituições de diversos níveis de ensino, na região do grande $A B C$ de São Paulo, analisou-se o controle da situação financeira, característica de cada grupo e nível de conhecimento sobre o tema finanças pessoais, onde concluiu-se que apesar da importância do tema para a sobrevivência das famílias, existe a falta de planejamento e conhecimento sobre as estratégias de controle de gastos, confecção de orçamentos e tipos de investimentos para a execução financeira do

The article presents an academic study on the importance of inserting financial education in the curriculum of schools and universities in Brazil, and from researches, address characteristics of the current level of knowledge provided by the teaching and learning processes in the various stages of education. The methodology used for the study was characterized by Exploratory Research with qualitative elements and Bibliographic Research. Research was carried out in institutions of different levels of education, in the region of the great $A B C$ of São Paulo, and analyzed the control of the financial situation, characteristic of each group and level of knowledge on the subject. It was concluded that despite the importance of the theme for the survival of families, there is a lack of planning and knowledge about spending control strategies, budgeting and types of investments for the financial execution of the family budget in the short, medium and long term.
\end{abstract} orçamento familiar a curto, médio e longo prazo.

Palavras-chave: Educação Financeira. Empréstimos. Orçamento Familiar.

Keywords: Financial education; Loans; Family budget.

${ }^{1}$ Pós-graduado em Controladoria e Finanças pela Universidade Metodista de SP (2016), graduado em Processos Gerenciais pela Universidade Metodista de SP (2014) e graduando em Ciências Contábeis pela Universidade Anhembi Morumbi. Atualmente é analista na administração de uma empresa de tecnologia bancária, desenvolvendo relatórios gerenciais e indicadores de gestão e otimização de processos.E-mail: elton.dias35@hotmail.com

${ }_{2}^{2}$ Aluno no programa de Doutorado em Educação pela Universidade metodista de SP (2021), Mestre em Administração pela Universidade Metodista de SP (2011) Mestre em Finanças com especialização em Risco pela USP (2000) - Pósgraduado em Administração Financeira (1997) e Tecnólogo Mecânico com especialização em Soldagem pela Faculdade de Tecnologia Prof. Luiz Rosa Fatec SP (1994). Atualmente é Diretor de Campus , Coordenador de Curso de Pós Graduação Lato Senso EAD em Logística e Professor Titular de Finanças na Universidade Metodista de São Paulo. E-mail: mdosantos@uol.com.br

Artigo recebido em: 24 de janeiro de 2020. Artigo aceito em 17 de dezembro de 2020. 


\section{Introdução}

Atualmente o estudo das finanças vem se desenvolvendo e alcançando os lares de milhões de famílias ao redor do mundo, porém no Brasil tal prática não é difundida de forma com que sua população possa se desenvolver e aplicar os conhecimentos em seu cotidiano.

Em documento recente do Ministério da Educação (MEC) indicando alterações na Base comum curricular podemos perceber a preocupação com a Educação Financeira em diversos pontos onde os alunos devem reconhecer dentro do processo de ensino, resolver e elaborar problemas que envolvam porcentagens dentro do contexto da educação financeira já a partir do sexto ano do ensino fundamental dois.

Segundo Branco (2015), o estudo das finanças contribui para que os indivíduos possam exercer sua cidadania em um mundo capitalista, a educação financeira abrange todos os indivíduos e compreende ações específicas a cada um, o hábito de poupar dinheiro e de compreender como funcionam as aplicações pode ser a diferença para uma vida financeiramente saudável ou não.

Um orçamento familiar é o primeiro passo para a educação financeira, através de um orçamento é possível alcançar objetivos de forma equilibrada, é importante que as crianças participem desse orçamento e saibam qual parcela das economias da família estão sendo destinadas para ele, estimular as crianças a criarem estratégias de investimento para alcançar objetivos simples desenvolverá o hábito de poupar e investir de forma consciente (SEBRAE, 2013).

Segundo Fernando Oliveira, presidente da Associação Portuguesa de Bancos (APB), a educação financeira deve ser abordada nas escolas, sendo necessário ensinar as crianças como o dinheiro circula, a importância de investimentos como a poupança, a segurança dos pagamentos e como tudo isso auxilia na geração de empregos e crescimento econômico de um país. (APB, 2016).

No âmbito internacional, a comunidade europeia realiza através da Initiatives of the European Banking Federation (EBF) o prêmio Europa Money Week, que busca incentivar organizações europeias a desenvolverem projetos para incentivar a educação financeira, que segundo a organização está baseada em 3 pilares fundamentais, "[...] Educação Financeira assenta em 3 pilares fundamentais: o conhecimento, as atitudes e os comportamentos." (EBF, 2017). 
Dentre os 23 países europeus que implementaram programas em busca de sensibilizar crianças e jovens para a importância da adoção de comportamentos ajustados no âmbito das suas opções financeiras, trazemos o exemplo de Portugal, no qual realizou-se o lançamento do site Boas Práticas Boas Compras, lançado com o objetivo de expandir o conhecimento financeiro na sociedade através de uma linguagem acessível. (APB, 2016).

No Brasil existem iniciativas de organizações não governamentais como a da AEF (Associação de Educação Financeira do Brasil), que através de projetos pedagógicos busca a inserção do tema no âmbito escolar, utilizando livros para alunos e professores com níveis distintos. (AEF, 2017)

A AEF através de um convênio firmado com o Banco Central do Brasil, realizou no mesmo ano algumas ações da Estratégia Nacional de Educação Financeira (ENEF), projeto que entre seus objetivos tem o de "aumentar a capacidade do cidadão para realizar escolhas conscientes sobre a administração dos seus recursos". (MEC, 2017)

O Brasil possui um histórico de grandes crises financeiras, dentre estas crises temos a crise hiperinflacionária da década de 1980 e 1990 que culminou em um período de grande recessão, suas altas taxas de juros e sua acentuada desigualdade social. É importante salientar que o Brasil foi um dos primeiros países a divulgar e estabelecer metas para inflação nacional, meta que atualmente é de 4,5\% com uma banda de 1,5\% (BACEN, 2017).

Dentre os indicadores capazes de refletir tal cenário temos o número de famílias inadimplentes no Brasil, que em agosto de 2019 totalizaram 63,4 milhões de pessoas, o equivalente a $40,6 \%$ da população brasileira, sendo que $31,2 \%$ dos inadimplentes é composto por jovens entre 18 a 25 anos. (SERASA, 2019)

Devido a este cenário é necessário que os projetos de educação financeira sejam intensificados, visando evitar novos períodos de crise e recessão. $\mathrm{Na}$ região do $\mathrm{ABC}$ no estado de São Paulo temos a presença do grupo DSOP, que aplica sua metodologia de ensino idealizada pelo doutor em finanças Reinaldo Domingos, que consiste em Diagnosticar, Sonhar, Orçar e Poupar. (DOMINGOS, 2017)

Em 2017 a metodologia DSOP foi implementada em algumas escolas na região do $\mathrm{ABC}$, dentre elas 2 escolas de São Bernardo do Campo, são elas o Colégio São Carlos e a Fundação Salvador Arena. (ABC), de acordo com Domingos, sua metodologia busca desenvolver as principais competências necessárias para que um 
cidadão possa exercer sua gestão financeira pessoal de forma consciente e saudável. (DOMINGOS, 2017)

Através de um estudo acadêmico o trabalho busca apresentar a importância de inserir a educação financeira na grade curricular das escolas e universidades do Brasil para que as pessoas desenvolvam um senso crítico e analítico sobre suas receitas e gastos, e a partir de pesquisas realizadas na região do $\mathrm{ABC}$ abordar as características regionais no ensino fundamental, médio e superior da região.

O tema de Educação Financeira Pessoal vem ganhando grande destaque no âmbito nacional e internacional, dentre os principais destaques temos o ganhador do prêmio Nobel de economia em 2017, Richard H. Thaler, professor da Universidade de Chicago. Thaler é coautor da teoria Nudge (Empurrão, em tradução livre), teoria que busca auxiliar pessoas comuns a tomarem decisões financeiras de forma racional (CASTRO, 2017).

Segundo Thaler as pessoas nem sempre tomam as decisões mais racionais em sua vida, e tal situação também ocorre quando o assunto é finanças pessoais, outros dois pontos abordados em sua teoria são os do Justo que aborda o quanto as pessoas estão dispostas a gastar em determinado produto e da percepção que elas possuem sobre os preços e o de Tentações a curto prazo, que desviam o planejamento financeiro para obter bens supérfluos (CASTRO, 2017).

O objetivo deste artigo concentra-se em construir o perfil de como o brasileiro estudante dos diversos níveis educacionais se relaciona com o dinheiro e os principais conhecimentos financeiros desta amostra da população brasileira.

O atual trabalho fará uso da pesquisa exploratória, com características quantitativas e pesquisa bibliográfica. A metodologia apresenta os processos realizados durante um determinado estudo. São apresentados os métodos, o tipo de pesquisa e os instrumentos utilizados (MASCARENHAS, 2012).

$\mathrm{Na}$ realização da pesquisa exploratória o modelo utilizado foi o de formulário digital, encaminhado ao público alvo do estudo; alunos do ensino fundamental, médio e superior. A investigação quantitativa baseia-se em técnicas de captação, apresentação e análise de dados que permitem a sua quantificação e o tratamento através de métodos estatísticos. (MASCARENHAS, 2012).

A pesquisa bibliográfica faz o estudo posteriormente sobre algo existente. Esta tem a função de colocar o pesquisador em contato direto com tudo aquilo que foi escrito 
sobre determinado assunto. A pesquisa bibliográfica é indispensável para identificação de fontes utilizadas no estudo (KOCHE, 2015).

\section{REFERENCIAL TEÓRICO}

Há muito que se falar do pensamento financeiro no Brasil e no mundo. O investimento e a história do dinheiro como moeda essencial de circulação e valorização entram em ascensão na idade média com as expedições marítimas e o apoio da Igreja Católica e dos Estados em encontrar novas terras e fomentar o comércio nas Índias e na dominação de novos territórios. $\mathrm{O}$ acúmulo de riquezas na época, como ouro, prata e joias era sinônimo de prosperidade, mesmo entendimento até hoje (MATIAS E FREITAS, 2012).

A riqueza, a distribuição da renda, a posse de escravos e de bens, os recursos financeiros das famílias e dos governos, a atividade comercial, os empréstimos, a tributação, a cobrança de juros, a valoração das mercadorias para a troca nos sistemas de escambo e na adoção de moedas, o fundamento dos preços, a interferência governamental no mercado e outras questões, impulsionaram o estudo de finanças. (MATIAS E FREITAS, 2012, p. 2)

O estudo das finanças se dá também com a preocupação dos grandes agricultores em aliar o lucro com a incidência exorbitante de impostos sobre os produtos e as terras, além da valorização dos bens, crédito e acúmulo de juros existentes (MATIAS E FREITAS, 2012).

Matias e Freitas (2012) comenta também que o investimento ganhou forma e evoluiu graças a inovação, a força dos pensamentos e reflexões filosóficas da Idade Antiga que se estende até os dias atuais. É interessante entender como a ciência financeira se aplica no cotidiano e como usá-la da melhor maneira na vida pessoal e profissional.

Para Gitman (2005) o investimento é a aplicação de recursos financeiros disponíveis em instrumentos que retornem lucros ou aumento do valor inicial. Muitos associam as aplicações ao ato de poupar, quando na verdade, além da poupança, essa prática tem como objetivo, o aumento de capital.

Quando você investe em uma organização - seja uma empresa ou uma entidade governamental -, ela lhe oferece um benefício esperado no futuro em troca do uso corrente de seus fundos. As organizações competem pelo uso de seus recursos. Terá seu dinheiro investido aquela que oferecer um benefício que você julgar melhor do que o oferecido pelas concorrentes. (GITMAN, 2005, p. 3) 
Poupar divisas é se abster do consumo imediato a fim de conquistar um consumo maior futuramente. Os objetivos básicos das pessoas que tomam essa atitude são: consumir mais, a curto prazo ou garantir mais reservas para um momento de maior necessidade (HALFELD, 2001).

O investidor deve ser um planejador, alguém otimista, que encontre a solução e a melhor saída para estruturar suas finanças e alcançar seus objetivos por prazos prédeterminados, são eles:

1. Longo prazo, como aposentadoria ou faculdade dos filhos, pois é esperado que o planejamento comece cinco anos antes;

2. Médio prazo é determinado pela quantidade de tempo da realização, de um a cinco anos, por exemplo, a compra da casa própria ou troca de carro;

3. E, por fim, curto prazo, considerado planos de alcance de até um ano e aplicações de emergência, como financiar as próprias férias ou algo do gênero.

Outra modalidade de divisão de objetivos é por categorias de preservação ou aumento de capital, ou seja, guardar o dinheiro ou aumentá-lo? A aplicação só funciona quando existe algum objetivo ao qual ela se destina, caso contrário, há grandes chances de se perder no meio do caminho.

É verdade também que investir em qualquer modalidade exige disciplina, o que se torna cada vez mais difícil atualmente, pois as pessoas acumulam dívidas com cartão de crédito, empréstimos ou outros gastos inerentes de suas necessidades e desejos. $\mathrm{O}$ hábito de registrar e mapear os gastos para identificar quais são os equívocos e desperdícios é bastante incomum, o que dificulta o indivíduo a estruturar as finanças e a estabelecer condutas diferentes com o próprio dinheiro.

É normal o investidor iniciante se sentir confuso ou perdido, porque investir é um constante aprendizado. É provável que os planos aconteçam em menos tempo e de forma positiva após o acúmulo de conhecimento. Dessa forma, investir se torna algo ousado, considerando que objeto de análise de qualquer investimento é o tempo, o objetivo, o risco a ser tomado, o cenário econômico atual, o tipo de investimento, entre outros aspectos que determinam o sucesso (CERBASI, 2013).

O investidor deve avaliar qual a aplicação mais adequada, de acordo com sua necessidade e retorno potencial, devendo contar também, com os riscos e medidas 
fiscais que devem ser respeitadas durante a operação. Além disso, é importante entender particularidades dos investimentos e qual o seu perfil de investidor (GITMAN, 2005).

De maneira simples, existem três tipos de investidores. Os conservadores procuram manter o máximo de segurança possível, evitando perdas em troca de uma rentabilidade inferior. O perfil moderado procura manter a segurança e rentabilidade equiparada, dispondo-se a correr um risco um pouco maior para ter alguma maximização na renda e por último, o arrojado tem a preferência por rentabilidade maiores, correndo grandes riscos de perda durante a operação. Por isso, conhecer o risco e o seu perfil de investidor antes de entrar num mercado é essencial (CVM, 2018).

\subsection{Investimentos}

Investimento é o comprometimento de dinheiro ou de outros recursos atuais, ou seja, no presente que proporcione a expectativa de colher benefícios futuros. (BODIE Z.; KANE A.; MARCUS A. J., 2014)

Para Cerbasi (2013) os investimentos financeiros são divididos em dois grandes grupos, são eles os investimentos de Renda fixa e os de Renda variável. Por meio do primeiro grupo é possível que o investidor saiba no momento da aplicação a quantidade de recursos financeiros que serão gerados, portanto, é ideal para pessoas com o perfil conservador.

A Caderneta de poupança é um investimento simples, conservador e com baixo risco, que permite qualquer pessoa fazer a aplicação. A rentabilidade é baixa e a longo prazo e nos períodos de inflação o rendimento dos juros é quase nulo. Em sua maior parte, os recursos da poupança são utilizados para o financiamento imobiliário, principalmente o SFH (Sistema Financeiro da Habitação) (CERBASI, 2013).

LCI (Letras de Crédito Imobiliário) e LCA (Letras de Crédito do Agronegócio) são muito parecidos com a Caderneta de Poupança. Os dois apresentam mais rentabilidade. Assim como o CDB são da modalidade de renda fixa, mas isentos de IR (CERBASI, 2013).

Ferreira (2015) entende que LCI (Letras de Crédito Imobiliário) e LCA (Letras de Crédito do Agronegócio) são títulos de crédito de renda fixa, o LCI é interligado por crédito imobiliário e garantido por hipotecas ou por alienação fiduciária de imóveis, já o LCA é bem semelhante, alterando somente sua ligação, pois foi criada para captar recursos para o setor de agronegócio.

Revista Eletrônica Gestão e Serviços v.11, n. 2, pp. 3167 - 3188, Julho/Dezembro 2020. ISSN Online: 2177-7284 e-mail: regs@metodista.br 
Os títulos públicos é outra opção para um investimento seguro que possibilita a capitalização de recursos por parte do Estado, com intuito de sanar dívidas públicas estaduais e municipais. A rentabilidade e segurança deste recurso estão diretamente ligados a gestão do governo. A venda destes títulos é realizada pelo Bacen, por leilões (CERBASI, 2013).

Debêntures são títulos emitidos por empresas que costumam envolver altos valores. Para efetivação desta modalidade é necessária a emissão de um documento chamado "Escritura de Emissão" que regulamenta todos os direitos e deveres do debenturista. A empresa que emite o título utiliza o dinheiro para giro de capital e o investidor recebe posteriormente o valor principal acrescido de juros periódicos. Apesar de envolver valor alto, também há possibilidade de pouca liquidez retornável (CERBASI, 2013).

Pinheiro descreve uma Debênture como:

Um título emitido por uma sociedade anônima, previamente autorizado pela CVM, com a finalidade de captar recursos de médio e de longo prazo, destinados normalmente a financiamento de projetos de investimento ou alongamento do perfil do passivo. Caracteriza-se como um título de valor mobiliário, com remuneração baseada em taxas de renda fixa. (PINHEIRO, 2016, p. 230)

Semelhantes aos Debêntures, os o Certificado de Depósito Bancário (CDB) e o Recibo de Depósito Bancário (RDB) são títulos emitidos por bancos. Podem ser préfixados, ou seja, o investidor prevê o lucro antecipadamente. Enquanto o primeiro é passível de negociação, o segundo não pode ser transferido por adotar uma política mais rígida. Ambos apresentam baixo risco (CERBASI, 2013).

Investir em Ações é bastante polêmico pelo alto risco. São negociadas por meio da Bolsa de Valores. O investidor torna-se sócio de uma empresa na proporção do percentual adquirido. Pode ser feito de várias maneiras, como por clubes de investimento, fundos de ações, corretoras ou individualmente. O retorno positivo é equivalente ao risco (CERBASI, 2013).

Por último e não menos importante, a Carteira administrada é um serviço e não um produto. Nada mais é do que contratar um administrador que possa gerir seus bens e seus investimentos, desde a ideia inicial até a gestão de projetos e sua finalização. Eles fazem tudo pelo investidor de uma forma ampla e não específica. A análise é completa de acordo com o perfil do cliente (CERBASI, 2013). 
Desta forma, entende-se por investimento um negócio, ao qual é necessário entender o perfil do aplicador, as condições que o envolve, sua perspectiva e, se possível, o resultado previsto.

\subsection{Taxa de juros}

Mundialmente diversos países adotam formas de controlar e aplicar as taxas de juros. Nos países desenvolvidos, as taxas tendem a serem mais baixas em comparação aos países emergentes. A taxa de juros possui diversas finalidades: auxiliar a captação de dinheiro pelos bancos; instrumento de política monetária; remunera os títulos públicos emitidos pelos governos; entre outros.

Desde a reestruturação do sistema financeiro mundial em 1945 os Estados Unidos possuem grande influência nos mercados de moedas e de taxas, denominada uma potência mundial. A diplomacia do dólar forte, é uns dos fatores que fortalece os EUA como uma potência mundial (TAVARES, 1985).

A taxa de juros americana sofreu um aumento de $0,25 \%$, o reflexo desse aumento, aumentaria a taxa de juros dos outros países; ocasionaria fuga de capitais para os Estados Unidos; valorização do dólar e desvalorização das demais moedas (VIEIRA, 2015).

As taxas de juros são utilizadas para captação de recursos disponíveis pelas instituições financeira que disponibiliza empréstimos de curto ou a longo prazo, com corretagem de juros. A forma de pagamento dessas dívidas é realizada através do Sistema de Amortização, é um método de cálculo da matemática financeira que abrangem os juros e o prazo acertados em contrato e definem qual a prestação mensal e que parcela dessa prestação abaterá aos poucos a dívida (FARO, 2013).

O professor Clovis de Faro (2013) em seu artigo "Uma nota sobre Amortização de dívidas e juros compostos", relata que existe sete modalidades de amortização:

- Sistema de pagamento único: ocorre um único pagamento sendo composto por capital somado a juros no final do período estipulado;

- Sistema de pagamento variável: são vários pagamentos diferenciados durante o período, sendo que os juros do saldo devedor sempre são pagos ao final de cada período;

- Sistema americano: é caracterizado por um único pagamento ao final do período, contudo os juros são calculados em várias fases do período; 
- Sistema de amortização constante (SAC): frequentemente o mais utilizado, os juros e o capital no SAC, são calculados uma única vez e divididos para o pagamento em várias parcelas durante o período;

- Sistema Price ou francês: geralmente usados em financiamentos de bens de consumo, todas as parcelas são iguais e com os juros já embutidos;

- Sistema de amortização misto: calcula-se o financiamento pelos métodos SAC e Price e faz-se uma média aritmética das prestações desses dois sistemas, resultando ao valor da prestação;

- Sistema de pagamento alemão: os juros são pagos antecipadamente, com prestações iguais;

Segundo a empresa Creditas (2019) no Brasil existem diversas fontes de captação de recursos financeiros. Algumas das principais fontes de créditos e popularmente conhecidas são: empréstimos pessoais, financiamentos, cheque especial e crédito consignado.

Captação de recursos financeiros em grande parte ocorre através da relação entre o agente deficitário, indivíduo carente de recursos extra de sua renda, com as instituições financeiras, detentora de recursos que suprem as necessidades dos agentes deficitários. A relação entre o agente deficitário e a instituição financeira é mediada por um contrato com certas condições, para que ambas partes saem satisfeitas (CARDOSO, 2002).

Empréstimo pessoal é um contrato entre uma instituição financeira e o agente deficitário, que recebe uma quantia que deverá ser devolvida à instituição financeira em um prazo determinado, acrescida de juros (AZEREDO E DUNCAN, 2002).

O uso do valor concedido pelo empréstimo é livre, ou seja, o indivíduo utilizará o recurso emprestado da forma que desejar, como não há necessidade de o indivíduo dar alguma garantia para a instituição pelo o empréstimo tomado, a mesma costuma cobrar uma taxa de juros mais alta que as demais linhas de créditos.

Cada instituição cobra sua taxa de juros, cabe ao consumidor analisar qual instituição é mais vantajosa. No mercado de empréstimo pessoal algumas linhas chegam a custar 7,3\% ao mês, correspondente a $132,91 \%$ ao ano. (ANEFAC, 2018) 
Segundo a pesquisa da ANEFAC (2018) Os economistas recomendam que em primeiro lugar, o consumidor deve organizar suas finanças antes de tomar um empréstimo, devendo levar em consideração o quanto ganha, quanto gastas para saber se poderá honrar ou não suas dívidas e analisar a real necessidade de tomar o empréstimo ou não.

Em segundo lugar o consumidor deve fazer uma pesquisa de mercado analisando as taxas das instituições pois os valores variam. Terceiro lugar o consumidor deverá estar atento a empréstimos facilitados, antes de tomá-los é necessário conferir a idoneidade da instituição financeira, analisando seu histórico para não cair em golpes.

Por fim o consumidor deve levar em conta o custo total da operação conhecido como CET (Custo Efetivo Total), que inclui os juros, todas as taxas e tributos envolvidos na operação, que devem ser levados em conta na escolha da instituição.

O financiamento é uma linha de crédito utilizada para a compra de algo específico sendo mais usada para a compra de imóveis e veículos. Essa operação possui taxa de juros mais baixa comparada a linha de empréstimo pessoal, pois o consumidor deve declarar a finalidade do dinheiro adquirido, geralmente o financiamento é acompanhado por uma garantia como por exemplo: alienação de uma hipoteca (imóvel), por isso os juros são mais baixos. O financiamento é indicado para bens de maior valor e de longo prazo (BACEN, 2017).

Cada instituição financeira cobra sua taxa de juros, é muito importante que o consumidor pesquise qual instituição oferta a taxa de juros menor, em alguns casos a diferença poder ser bem significativa.

Outra modalidade de crédito adotada no Brasil é o Cheque Especial, sendo um valor que o Banco disponibiliza na conta corrente, ou seja, o consumidor pode usar o cheque especial, quando sua despesa exceder sua renda interna, necessitando de outra renda externar (SOUSA, 2008).

Contudo, toda vez que o cliente utilizar o cheque especial, pagará o Imposto sobre Operações Financeiras, juntamente com os juros proporcionais ao tempo em que o cheque especial for consumido, o grande diferencial do cheque especial das demais linhas de créditos é o valor de juros, podendo a chegar a 14\% ao mês.

As taxas do cheque especial são abusivas, o banco utiliza diversas técnicas de marketing para atrair o consumidor, disponibilizando o dinheiro de fácil alcance, com o valor mais caro (BARONE, 2008). 
O Crédito Consignado também é popularmente conhecido, sendo um tipo de crédito oferecido aos funcionários de empresas privadas, pensionistas e aposentados, são empréstimos com juros bem abaixo do mercado, em que as parcelas são descontadas diretamente do salário do funcionário, aposentado ou pensionista. (BARONE, 2008).

Existem duas fontes de garantidora do pagamento desse empréstimo: um é garantido pelo Instituto Nacional da Seguridade Social com desconto direto da aposentadoria do credor, o outro pode der firmado pelas instituições financeiras acordadas com a Previdência Social. Com objetivo de minimizar o mau uso desse recurso o governo estabeleceu um endividamento ou comprometimento de $30 \%$ do salário (BARONE, 2008).

A contabilidade vem desde os tempos mais remotos, auxiliando a controlar nossas finanças, patrimônios e recursos disponíveis. Usamos essa ferramenta ao nosso favor, uma vez que a memória já não conseguia armazenar todos os dados.

A necessidade de guardar memória dos fatos ocorridos, com a riqueza patrimonial, gerou critérios de escrita em formas progredidas mesmo nas civilizações mais antigas como a Suméria; há cerca de 6.000 anos, encontram-se já registros em peças de argila que indicam tais evoluções. Pequenas tábuas de barro cru serviram para gravar, de forma simples, fatos patrimoniais diversos [...]. Da argila crua, de menor resistência, passou-se à "argila cozida", para melhor conservar os registros (em tábuas muito pequenas). Ao longo da história o progresso dos materiais empregados foi ditando, também, o aprimoramento dos critérios de escrituração contábil (SÁ, 1994, p. 13).

Fluxo de Caixa é o conceito essencial para se obter uma boa gestão financeira, ela melhora a visão das movimentações de dinheiro que a pessoa tem e terá. É importante mantê-lo sempre atualizado e com o máximo de informações antecipadas possíveis, para visualizar assim as movimentações futuras e evitando que se tenha atitudes precipitadas. O fluxo de caixa também muito utilizado por empresas para gestão e controle financeiro é uma ótima ferramenta a ser utilizada no controle das finanças pessoais (SEBRAE, 2011).

Segundo Sebrae (2011, p. 1) "De fácil elaboração para as empresas que possuem os controles financeiros bem organizados, ele deve ser utilizado para controle e, principalmente, como instrumento na tomada de decisões".

Para elaborar um orçamento familiar é necessário entender o conceito de receitas e despesas, princípios contábeis, receitas são todas as formas de renda e dinheiro que 
entra no caso no orçamento familiar, e as despesas são todos os gastos da família, todas as contas (CAMARGO, 2017).

Um orçamento familiar deve ser a principal preocupação para uma família atualmente, com ele a família passa a se planejar financeiramente e evitar imprevistos no orçamento. Em 2008/2009 na Pesquisa de Orçamento Financeiro (POF) 75,2\% das famílias declararam ter "algum grau de dificuldade para chegar ao final do mês com o rendimento que recebiam" (IBGE, 2010).

Para um bom planejamento temos que reunir todos os membros da família ou todos que participam das receitas da casa para elaborar ele da melhor forma a evitar erros e esquecimentos. "Ter objetivos comuns e conversa franca sobre as finanças da família é um bom caminho para engajar todos na batalha pela economia (CAMARGO, 2017)

Quando bem feito possibilita às famílias poupar dinheiro, ter controle dos gastos e até organizar a realização de objetivos, como a compra de uma casa ou carro, uma viagem etc. É fundamental estabelecer uma meta para o orçamento, nem que seja cortar os gastos, mas tudo será possível a partir de um planejamento.

Primeiramente deve-se listar todas as despesas fixas da família, conta de água, energia, aluguel, condomínio etc. Depois todas as despesas anuais, como Imposto sobre a Propriedade de Veículos Automotores (IPVA) e Imposto Predial e Territorial Urbano (IPTU), e mensais como a mensalidade de um curso ou faculdade, compra do supermercado, ou compras parcelas em longo prazo como financiamento de carro e moto. Também é importante não se esquecer das despesas que não costumamos contar, como o dinheiro da feira de domingo e o dinheiro para comprar pão na padaria todos os dias. Gastos com alimentação na escola dos filhos, mesadas, dinheiro para transporte também são muito importantes. Como temos no exemplo a seguir:

Imagem 01 - Relação de ganhos

Fonte: Elaborado pelos próprios autores.

\begin{tabular}{|c|c|c|c|c|c|c|c|c|c|c|c|c|}
\hline Salários & Janeiro & Fevereiro & Março & Abril & Maio & Junho & Julho & Agosto & Setembro & Outubro & Novembro & Dezembro \\
\hline & & & & & & & & & & & & \\
\hline & & & & & & & & & & & & \\
\hline Contas Fixas & - & - & - & - & - & - & - & - & - & - & - & - \\
\hline & & & & & & & & & & & & \\
\hline & & & & & & & & & & & & \\
\hline & & & & & & & & & & & & \\
\hline & & & & & & & & & & & & \\
\hline & & & & & & & & & & & & \\
\hline Contas Variáveis & - & - & - & - & - & - & - & - & - & - & - & - \\
\hline & & & & & & & & & & & & \\
\hline & & & & & & & & & & & & \\
\hline & & & & & & & & & & & & \\
\hline & & & & & & & & & & & & \\
\hline Objetivo & - & - & - & - & - & - & - & - & - & - & - & - \\
\hline & & & & & & & & & & & & \\
\hline Total & & & & & & & & & & & & \\
\hline Total & & & & & & & & & & & & \\
\hline
\end{tabular}


É fundamental ter uma média dos últimos gastos com cartão de crédito, uma estimativa de quanto se gasta com a manutenção do carro mensalmente e quanto se gasta com combustível, que podem ser baseados nas contas dos anos anteriores, a princípio pode ser complicado, mas com um bom controle em poucos meses a família consegue enxergar para onde está indo toda a renda e se planejar financeiramente.

Leal e Melo (2008) enfatiza o planejamento financeiro pessoal dizendo que o mesmo possibilita que o indivíduo verifique melhor e gerencie suas contas e investimentos de forma que acabe com seus problemas financeiros ou os reduza significativamente.

Com as receitas são da mesma forma, deve-se listar as receitas fixas e com o valor líquido para não haver surpresas no final do mês, também deve aparecer todas as receitas variáveis com um valor médio, de todos os membros da família.

Também é importante durante todo o processo que todos colaborem para ficar dentro do orçamento e pelo menos uma vez na semana se reunirem para discutir como está o orçamento, até ele se encaixar na vida da família, para o sucesso do planejamento é fundamental estabelecer metas reais, pois uma meta muito acima ou o corte de muitos gastos radicalmente pode provocar desmotivação do objetivo e de seguir o planejamento.

\section{ANÁLISE DE DADOS}

A pesquisa realizada com os 401 estudantes de ensino superior, demonstra que 82 deles se encontram em situação de inadimplência no mercado. Considerando o perfil, verifica-se que existem diversas variáveis que influenciam e colaboram com a situação em questão.

O gráfico abaixo, aponta que $62,19 \%(1+4)$ das pessoas inadimplentes, utilizam cartões de crédito com frequência, enquanto que, apenas $25,61 \%$ (2) deixaram de utilizar a ferramenta e $17,20 \%$ (3) não possuem cartões. Este fato contribui para que os compradores não consigam honrar suas dívidas, aumentando a quantidade de juros a serem pagos e o tempo para cumprir o pagamento. 
Gráfico 01 - Inadimplentes vs perfil de uso de cartões

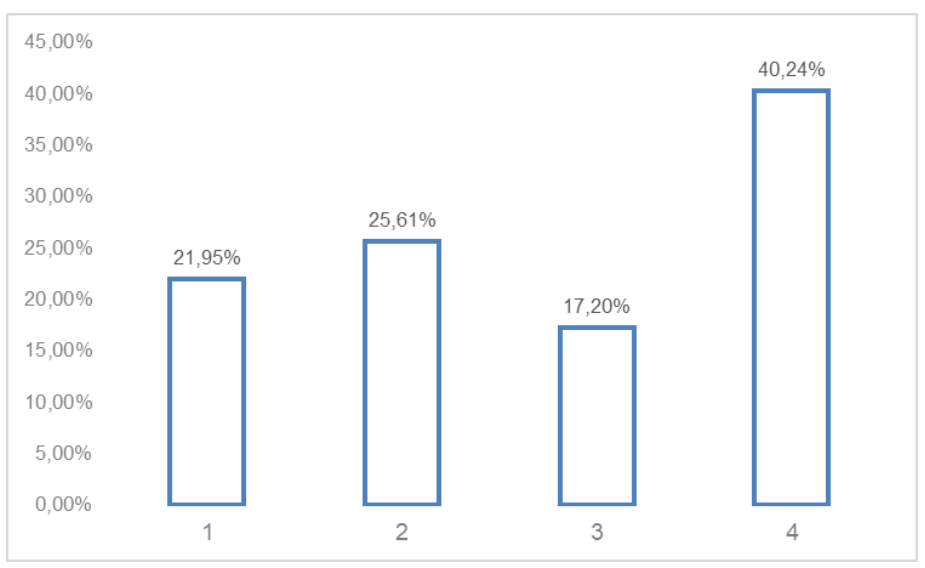

Fonte: Elaborado pelos próprios autores.

A pesquisa aponta que $59,09 \%$ dos inadimplentes já tomaram empréstimos no mercado. Situação que pode ser compreendida como consequência do acumulo de dívidas e falta de controle das despesas individuais.

A análise permitiu também, compreender fatores que podem influenciar as pessoas a perderem o controle de sua situação financeira ou até mesmo não conhecerem ferramentas que possam ser úteis para facilitar uma gestão mais adequada e assertiva.

Inicialmente, constata-se que, todas as pessoas enquadradas no perfil de inadimplência, estão na faixa etária dos 17 aos 26 anos. Entende-se que nesse período, se gasta muito com investimentos a fim de promover o bem-estar no futuro, como cursos de graduação, cursos complementares e até mesmo viagens em busca de mais qualificação. Entretanto, a pesquisa aponta que grande parte dos gastos de pessoas nessa faixa etária, está sendo destinado ao lazer e diversão, tendo como consequência, o desperdício de recursos que dificilmente serão recuperados.

Gráfico 02 - Destinação de gastos dos jovens

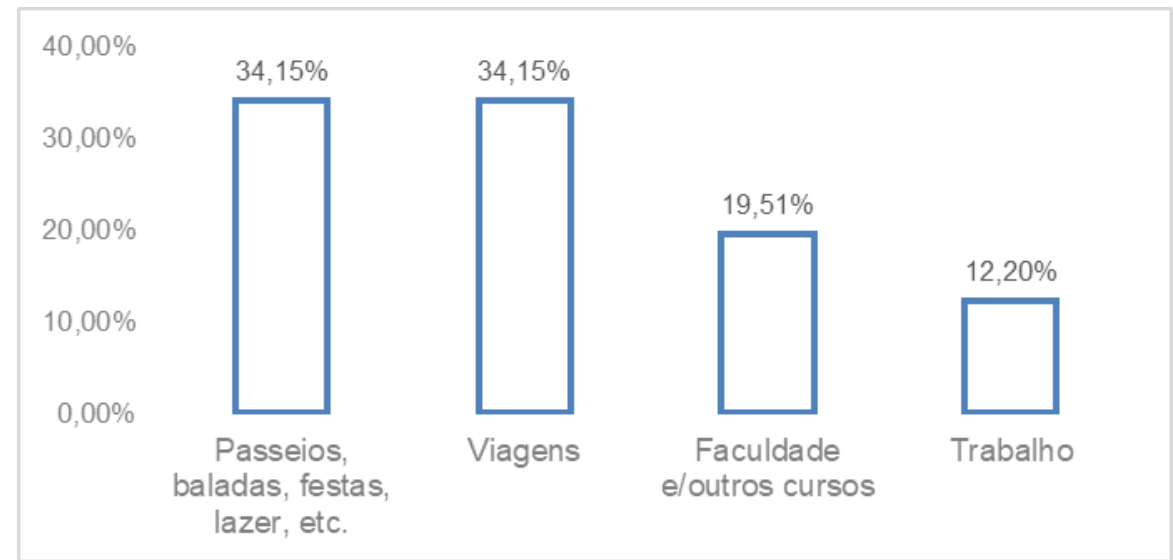

Fonte: Elaborado pelos próprios autores. 
Em questão do conhecimento repassado através das gerações e as técnicas necessárias para lidar com os recursos financeiro, a pesquisa demonstra que o perfil inadimplente, tem um histórico familiar, pois $82,27 \%$ dos respondentes, informaram que seus pais não são organizados financeiramente, o que pode explicar a importância da educação financeira na vida futura das famílias.

Além disso, 82,04\% das pessoas informaram que não aprenderam ou aprenderam sozinhos a fazer a gestão de suas dívidas, contribuindo com o fato da grande necessidade que existe em educar e disciplinar as pessoas para que possam conhecer e participar de forma mais ativa e consciente do mercado financeiro.

De acordo com a pesquisa, nota-se que $36,66 \%$ das pessoas que não fazem a análise das receitas e despesas do próprio cotidiano e, desse total, 20,70\% estão sempre no vermelho. Por outro lado, $63,34 \%$ das pessoas fazem o controle de seus ganhos e perdas, sendo que, $45,14 \%$ deles, conseguem administrar as contas e investimentos que têm.

Ainda tratando sobre o aspecto do controle pessoal financeiro, verifica-se que grande parte dos ganhos são destinados a lazer/passeios. Ou seja, dentre as variáveis, não há uma quantidade satisfatória de recursos destinados à investimentos, seja no âmbito financeiro ou para ascendência de carreira. São 65,59\% dos recursos destinados a atividades que não geram retorno ou contribuem para o crescimento pessoal e auxílio na carreira profissional.

O gráfico aponta que de todos os alunos entrevistados, $71,43 \%$ deles mantém uma poupança ou guardam os seus rendimentos de alguma forma, mas não atuam com investimentos.

Observa-se que grande parte dos respondentes costumam direcionar seus rendimentos para lazer e diversão $(65,73 \%)$, representando a falta de programação para coisas futuras e mantendo um ciclo que já foi demonstrado na pesquisa com estudantes da universidade. Grande parte das pessoas, destinam seus ganhos em questões supérfluas e sem retorno financeiro. 
Gráfico 03 - Incentivo dos pais para seus filhos economizarem

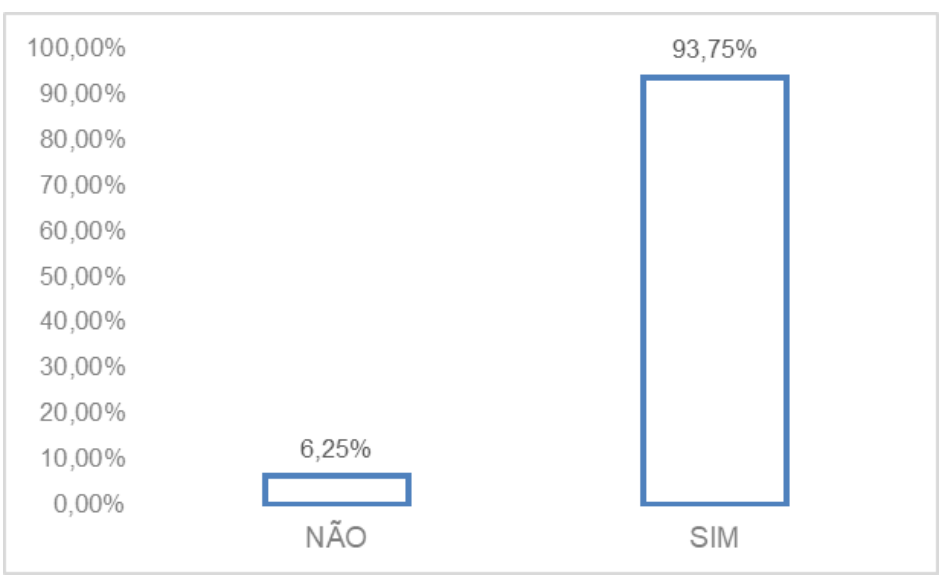

Fonte: Elaborado pelos próprios autores.

Observa-se um percentual de quase $100 \%$ de incentivo dos pais aos filhos, para que estes, tenham o hábito de economizar seus rendimentos. Nota-se que a efetividade do incentivo é muito baixa, devido aos resultados anteriores, onde grande parte dos ganhos são destinados em assuntos não produtivos ou que retornem mais dinheiro/ofereçam comodidade no futuro.

Nota-se que há uma aceitação positiva de $81,25 \%$ por parte dos entrevistados em aprender sobre finanças pessoais, corroborando com a finalidade de ser implantado cursos e oficinas que auxiliem os alunos a adquirirem mais conhecimento na área em questão.

A pesquisa realizada com alunos do ensino fundamental, apresenta novas perspectivas acerca do assunto, tendo em vista que as pessoas nessa fase da vida, ainda não tem noções e conhecimentos sólido sobre o assunto e dependem totalmente dos pais. A pesquisa aponta que $83,33 \%$ dos respondentes tem inclinação para fazer economia a fim de conquistar um bem a longo prazo.

A escolha entre o lanche de casa e da cantina, considerando os alunos que recebem mesada, pode revelar a tendência deles em relação aos ganhos que obtêm. Nota-se que $64,29 \%$ deles costumam levar lanche de casa, apontando um perfil econômico, pois não gasta-se os recursos com algo que se pode ter em casa. Entretanto, $35,71 \%$ destinam parte dos ganhos com lanches na cantina, revelando a despreocupação com uma destinação mais assertiva dos recursos. 
Gráfico 04 - Material escolar

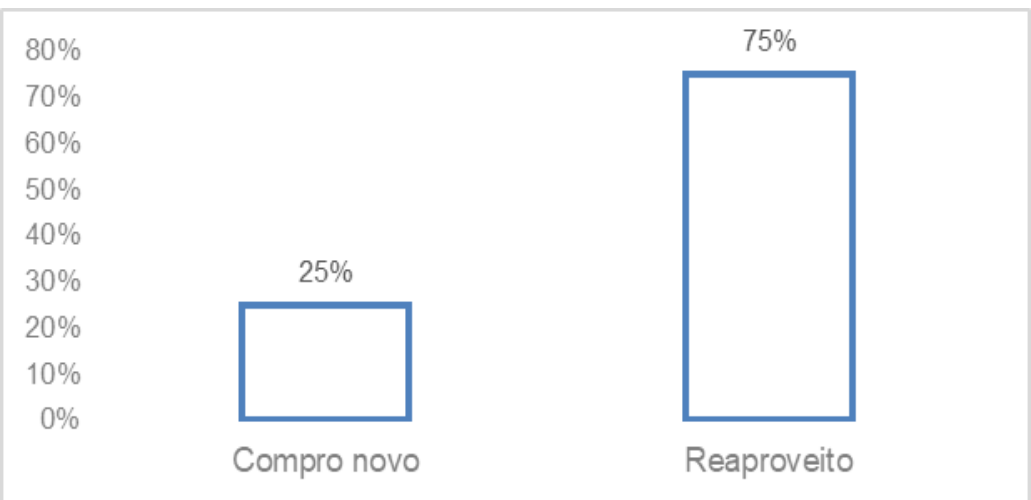

Fonte: Elaborado pelos próprios autores.

O material escolar auxilia a compreensão da atitude dos pais em relação aos cuidados com os filhos. Isso ocorre devido a compra desses itens está sob responsabilidade dos pais, e esses julgam por último se, haverá ou não a compra de produtos novos. Sendo assim, conclui-se que $75 \%$ deles preferem reaproveitar os materiais. Essa taxa pode aumentar com o decorrer dos anos, pois estudantes da escola pública recebem material da escola e precisam comprar cada vez menos itens no mercado externo. A taxa mais baixa, tende a manter valores baixos, pois alunos de escolas particulares - a "pedido" da instituição - tem a necessidade de adquirir mais livros, ou itens novos com o decorrer dos anos.

Gráfico 05 - Destinação da mesada

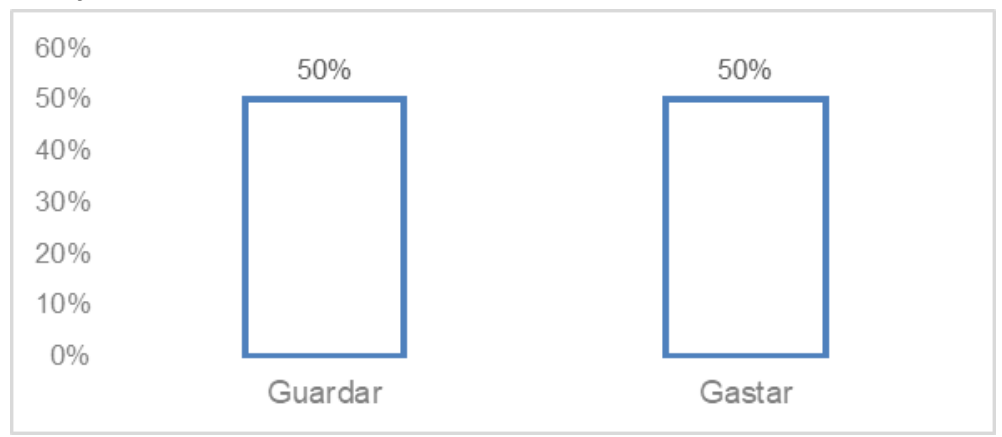

Fonte: Elaborado pelos próprios autores.

Dentre os alunos que recebem mesada dos pais, percebe-se que metade deles costumam guardar o dinheiro, enquanto a outra, gasta. 
Gráfico 06 - Tipo de escola vs destino dos ganhos

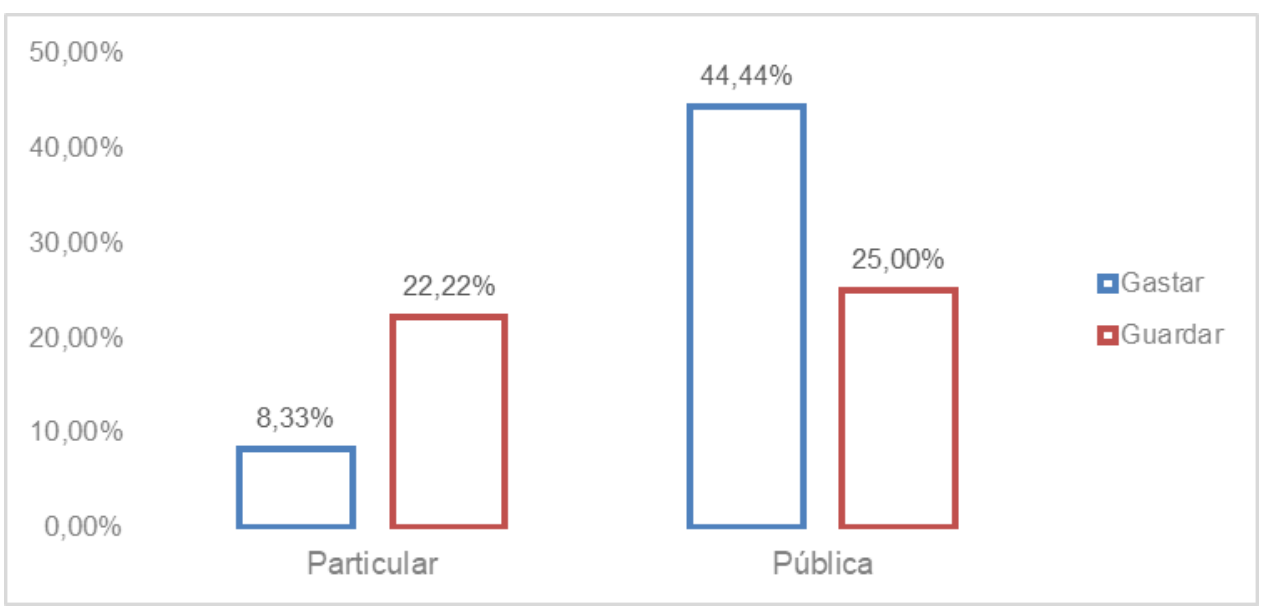

Fonte: Elaborado pelos próprios autores.

O gráfico acima representa a decisão dos alunos de escola particular e pública. Observa-se que na escola particular, a maior parte dos alunos costumam a guardar o seu dinheiro, e menos de 10\% deles tem o hábito de gastar. Entretanto, em escolas públicas, os valores se invertem: A maior parte deles, costumam gastar o dinheiro que recebem, enquanto apenas $25 \%$ realizam economias. $\mathrm{O}$ fato pode ser explicado por conta do tipo de educação que é passado aos alunos e também pela diferença de classes entre os nichos pesquisados.

\section{CONSIDERAÇÕES FINAIS}

Com a implementação da educação financeira nas escolas, universidades e em parceria com temas já constantes na grade curricular, reforçado através das recentes alterações na Lei de diretrizes e Bases da Educação (LDB) e com a implementação de cursos de Educação Financeira dentro dos diversos currículos e projetos pedagógicos dos cursos em universidades do Brasil, incentivará a capacidade das pessoas e famílias a planejar e organizar os recursos financeiros, a fim de atingir seus objetivos e reduzir o grau de inadimplência quando se busca alguma forma de financiamento, para empreender ou adquiri um bem.

Através das pesquisas realizadas, pode-se observar que existe um grande interesse em controle financeiro e pelos tipos de investimentos que demandam conhecimentos sobre rentabilidade, perfis de risco e também ciência dos riscos dos diversos investimentos, aliado ao conhecimento de políticas econômicas e mercados. 
A pesquisa foi de suma importância, servindo com que as pessoas reduzam gastos e desperdícios no núcleo familiar, promovendo maior poder de negociação no momento de aquisição de algum bem ou melhor adequação dos investimentos aos objetivos pessoais e familiares de curto, médio e longo prazo. A redução do nível de endividamento e inadimplência é um indicador significativo da eficácia da implementação da educação financeira, medida que apresenta valor na sociedade brasileira, que apresenta indicadores inadequados minando os orçamentos pessoais e familiares.

\section{REFERÊNCIAS}

AEF. Sobre nós. Disponível em: <http://www.aefbrasil.org.br/>. Acesso em: 26 agosto 2017.

ANEFAC. Pesquisa de Juros. Disponível em: <

https://www.anefac.com.br/uploads/arquivos/2018315161835543.pdf $>$. Acesso em: 10 out. 2018 .

APB. Revista Educação Financeira. Disponível em:

$<$ http://www.apb.pt/content/files/Revista_Educao_Financeira.pdf $>$. Acesso em: 26 ago. 2017.

AZEREDO, Beatriz; DUNCAN, Pedro Gomes (Org.). A experiência da Área de Desenvolvimento Social no período 1996/2002. Rio de Janeiro: Banco Nacional de Desenvolvimento Econômico e Social, 2002.

BANCO CENTRAL. FAQ - Empréstimos e financiamentos. Disponível em: $<$ http://www.bcb.gov.br/pre/bc_atende/port/servicos9.asp>. Acesso em: 17 de out. 2017.

BANCO CENTRAL DO BRASIL. ENEF. Disponível em:

$<$ http://www.bcb.gov.br/pre/pef/PORT/enef.asp>. Acesso em: 26 ago. 2017.

BANCO CENTRAL DO BRASIL. Histórico de Metas para Inflação no Brasil.

Disponível em: <http://www.bcb.gov.br/Pec/metas/TabelaMetaseResultados.pdf $>$. Acesso em: 26 ago. 2017.

BARONE, F. M. Acesso ao crédito no Brasil: evolução e perspectivas. 2008. Disponível em $<$ http://www.scielo.br/scielo.php?script=sci_arttext\&pid=S0034$76122008000600012>$. Acesso: 16 de out. 2017.

BODIE Z.; KANE A.; MARCUS A. J.. Fundamentos de Investimentos. 9 ed. São Paulo: AMGH, 2014.

BRANCO. A. Matemática financeira aplicada. São Paulo: Cengage Learning. Ed $\mathrm{n}^{\circ}$ $15,2016$.

CASTRO, José. O que deu a Richard Thaler o Nobel de economia em 2017.

Disponível em: <https://www.nexojornal.com.br/expresso/2017/10/09/O-que-deu-aRichard-Thaler-o-Nobel-de-economia-em-2017>. Acesso em: 22 out. 2017.

Revista Eletrônica Gestão e Serviços v.11, n. 2, pp. 3167 - 3188, Julho/Dezembro 2020. ISSN Online: 2177-7284 e-mail: regs@metodista.br 
CAMARGO, Sophia. Como organizar o orçamento doméstico em quatro passos. Disponível em: <https://economia.uol.com.br/financaspessoais/noticias/redacao/2015/06/09/como-organizar-o-orcamento-domestico-emquatro-passos.htm>. Acesso em: 23 abr. 2017.

CARDOSO, Ruth. Et. al. Comunidade solidária: fortalecendo a sociedade, promovendo o desenvolvimento. Rio de Janeiro: Comunitas, 2002.

CERBASI, Gustavo. Investimentos inteligentes - Estratégias para multiplicar seu patrimônio com segurança e eficiência. São Paulo: Editora Sextante, 2013.

Creditas. Tipos de empréstimos: entenda as 7 modalidades mais comuns. Disponível em: < https://www.creditas.com/exponencial/emprestimos-modalidades-comuns/>. Acesso em: 30 nov. 2019.

CVM. Portal do investidor: Princípios do investimento. Disponível em: $<$ https://investidor.cvm.gov.br/menu/primeiros_passos/principios_investimento.html $>$. Acesso em: 15 abr. 2018.

DOMINGOS. Sobre nós. Disponível em: $<$ http://www.reinaldodomingos.com.br/>. Acesso em: 28 set. 2017.

EBF. Initiatives of the European Banking Federation. Disponível em: $<$ http://www.ebf.eu/about-us/>. Acesso em: 26 ago. 2017.

FARO, Clovis de. Uma nota sobre amortização de dívidas: juros compostos e anatocismo. 2013. Disponível em:

http://www.scielo.br/scielo.php?script=sci_arttext\&pid=S0034-71402013000300002. Acesso em: 17 out. 2017.

FERREIRA, Roberto G. Tesouro Direto e Outros Investimentos Financeiros. São Paulo. Atlas S.A. 2015. Disponível em: < https://integrada.minhabiblioteca.com.br/\#/>. Acesso em: 20 mai. 2018.

GITMAN, Lawrence J. JOEHNK, Michael D. Tradução de Maria Lúcia Leite Rosa, revisão técnica de Elias Pereira. Princípios de investimentos. São Paulo: Pearson Addison Wesley, 2005.

HALFELD, Mauro. Investimentos: Como administrar melhor seu dinheiro. $1^{\mathrm{o}}$ edição. Editora Fundamento Educacional. São Paulo. 2001.

IBGE. POF 2008/09 mostra desigualdades e transformações no orçamento das famílias brasileiras. Disponível em: $<$ https://agenciadenoticias.ibge.gov.br/agenciasala-de-imprensa/2013-agencia-de-noticias/releases/13846-asi-pof-2008-09-mostradesigualdades-e-transformacoes-no-orcamento-das-familiasbrasileiras\#: :text=Em $\% 202008 \% 2 \mathrm{~F} 09 \% 2 \mathrm{C} \% 20$ cerca $\% 20 \mathrm{de}$,foi $\% 20 \mathrm{de} \% 2085 \% 2 \mathrm{C} 0 \% 2$ 5.>. Acesso em: 21 mai. 2018.

KOCHE, José Carlos. Teoria da Ciência e Iniciação à Pesquisa. Petrópolis. Vozes. 2015. 
LEAL, Douglas Tavares Borges; MELO, Sheila de. A contribuição da educação financeira para a formação de investidores. In: $2^{\circ}$ Congresso UFSC de Controladoria e Finanças \& Iniciação Científica em Contabilidade, 2008, Florianópolis. Anais Eletrônicos... Florianópolis: Universidade Federal de Santa Catarina, 2008. Disponível em: Acesso em: 19 abr. 2018.

MASCARENHAS, Sidnei A. Metodologia Científica. São Paulo. Pearson 2012.

MATIAS, Prof. Dr. Alberto Borges; FREITAS, Zípora de Campos. A evolução do pensamento financeiro: uma investigação sobre a teoria financeira desde o início das civilizações até a atualidade. 2012, pág. 2 Disponível em:

$<\mathrm{http}$ ://www.cepefin.org.br/publicados_pdf/evolucao_pensamento_financeiro.pdf $>$. Acesso em: 25 mar. 2018.

MEC, Ensino de educação financeira é importante para desenvolvimento de crianças e adolescentes. 2017. Disponível em: http://portal.mec.gov.br/ultimasnoticias/211-218175739/58211-ensino-de-educacao-financeira-e-importante-paradesenvolvimento -de-criancas-e-adolescentes. Acesso em: 28 março 2018.

PINHEIRO, Juliano Lima. Mercado de Capitais. 8. Ed. São Paulo: Atlas, 2016.

SÁ, Antônio Lopes de. Teoria da contabilidade superior: História e Filosofia da Contabilidade. Belo Horizonte: Siracusa, 1994, p.13.

SERASA. Um em cada cinco inadimplentes no Brasil tem entre 41 e 50 anos, revela Serasa Experian. Disponível em: $<$ https://www.serasaexperian.com.br/sala-deimprensa/um-em-cada-cinco-inadimplentes-no-brasil-tem-entre-41-e-50-anos-revelaserasa-experian>. Acesso em: 29 ago. 2019.

Sebrae. Análise e Planejamento Financeiro - Manual do Participante. Brasília, 2011. Disponível em: http://www.sebrae.com.br/Sebrae/Portal\%20Sebrae/Anexos/0_fluxo-decaixa.pdf. Acesso em: 25 de mar. de 2018.

Sebrae. Pessoa Física - Planejamento e Controle Financeiro Pessoal. Salvador, 2013. Disponível em:

$<$ https://bibliotecas.sebrae.com.br/chronus/ARQUIVOS_CHRONUS/bds/bds.nsf/3c27b 46226d68958621f1f121cdf8f22/\$File/4577.pdf>. Acesso em: 25 de mar. de 2018.

TAVARES, Maria da Conceição. A Retomada da Hegemonia Norte-Americana. 1985. Disponível em: <http://www.rep.org.br/pdf/18-1.pdf>. Acesso: em 25 mar. 2018.

VIEIRA, Clodoir. Aumento dos juros nos EUA: como isso afeta o Brasil e seu bolso. 2015. Disponível em $<$ https://economia.uol.com.br/financaspessoais/noticias/redacao/2015/12/16/aumento-dos-juros-nos-eua-como-isso-afeta-obrasil-e-o-seu-bolso.htm> Acesso em: 16 out. 2017. 